\title{
Nonsurgical collection and nonsurgical transfer of preimplantation embryos in the domestic rabbit (Oryctolagus cuniculus) and domestic ferret (Mustela putorius furo)
}

\author{
J. D. Kidder ${ }^{1}$, P. J. Roberts ${ }^{2}$, M. E. Simkin ${ }^{1}$, R. H. Foote ${ }^{1 *}$, and M. E. Richmond ${ }^{3}$ \\ ${ }^{1}$ Department of Animal Science, Cornell University, Ithaca, NY 14853; 'Department of Veterinary Clinical Sciences, \\ New York State College of Veterinary Medicine, Cornell University, Ithaca, NY, 14853; and ${ }^{3}$ New York Cooperative Fish and \\ Wildlife Research Unit, Cornell University, Ithaca, NY 14853, USA
}

\begin{abstract}
The objective of this study was to develop nonsurgical methods of embryo collection and transfer in domestic rabbits (Oryctolagus cuniculus) and domestic ferrets (Mustela putorius furo) to serve as models for use in mammals in which surgical procedures are the usual means for applying embryo transfer technology. Specially designed transcervical catheters were used together with a fibre optic endoscope to visualize and then catheterize the rabbit and ferret cervices. Five consecutive transcervical uterine flushes in each of eight superovulated female rabbits $78-89 \mathrm{~h}$ after an ovulatory injection of LH resulted in the retrieval of 187 embryos, for an average of 23 embryos per rabbit. A total of 116 embryos were nonsurgically transferred to the uteri of ten recipients, and resulted in 23 young $(20 \%)$. Eight rabbits $(80 \%)$ produced young with an average litter size of 2.88 (range 1-7). Ten consecutive transcervical uterine flushes in each of 37 female ferrets $145-178 \mathrm{~h}$ after an ovulatory injection of hCG resulted in the retrieval of 324 embryos, an average of 8.76 embryos per ferret. A total of 251 embryos from 27 donors were nonsurgically transferred to the uteri of 31 recipients, and resulted in 65 young (26\%). Twenty-eight of the recipients $(90 \%)$ were initially pregnant, as indicated by postpartum necropsies, and twenty-two ferrets $(71 \%)$ produced young. The average litter size was 2.95 (range 1-7). This is the first report of live births resulting from the nonsurgical collection of embryos from a donor followed by nonsurgical transfer of those same embryos to a synchronous recipient. The methods reported here can serve as models for use in other mammals in which direct visualization and manipulation of the cervix are not possible, and will be particularly useful in endangered species.
\end{abstract}

\section{Introduction}

Embryo transfer technology has enhanced the reproductive potential of several livestock species and has the potential for aiding in the assisted reproduction of wild mammals, particularly for the captive propagation of rare or endangered species (Wildt $e t$ al., 1986). The most extensive application of embryo transfer has been in large domestic animals in which manual manipulation of the transcervical catheters used for embryo collection and transfer is possible (Seidel, 1981; Anderson, 1983; Foote, 1987). Embryo transfer was first accomplished in domestic rabbits (Heape, 1890). Since that time, embryo transfer in rabbits has contributed greatly to studies that have advanced our knowledge of reproductive and developmental biology (Adams, 1982).

A variety of surgical methods have been used to collect and transfer embryos in the rabbit (Pincus and Enzmann,

${ }^{*}$ Correspondence.

Revised manuscript received 23 November 1998.
1932; Chang, 1950; Adams, 1962; Hafez, 1962; Maurer et al., 1968; Yang and Foote, 1987). Transcervical transfer of embryos was accomplished by surgically accessing the cervices through the vaginal wall (Adams, 1956; Dauzier, 1962; Testart, 1969).

The major limitation to development of embryo transfer technology in most mammals is the difficulty in traversing the cervix. Surgical intervention can overcome this problem, but invasive procedures can cause tissue adhesions and other surgical complications that may limit future embryo recovery and compromise the ability of an animal to reproduce naturally. These risks are particularly important considerations when working with rare or endangered species. Torres and Sevellec (1987) have documented the detrimental effects of repeated surgical recoveries of embryos on the fertility of the donors. Wildt and Goodrowe (1989) suggest that extremely careful surgical procedures may allow 2-4 embryo recovery operations before tissue adhesions would be inhibitory.

Laparoscopic procedures, which require minor abdominal 
surgery, have been developed for application to mammals that are too small for transcervical embryo transfer (Dukelow, 1971; Wildt, 1980; Wildt et al., 1986). Two methods of transcervical catheterization without direct cervical visualization or manipulation have been reported in domestic cats and were used with limited success to collect embryos (Hurlbut et al., 1988) and to transfer embryos (Swanson and Godke, 1994). A nonsurgical approach has been used with some success to collect embryos expelled into the vagina in domestic rabbits after administration of various hormone regimens (Tsutsumi et al., 1976; Takeda et al., 1977, 1979; Tsutsumi et al., 1979; Gajda et al., 1988).

The objectives of this study were: (1) to develop a system using fibre optic endoscopy that would allow nonsurgical catheterization of the rabbit and ferret cervices; (2) to collect embryos nonsurgically from donors; and (3) to transfer these embryos nonsurgically to the uteri of recipients to produce live young. This paper reports the first successful nonsurgical techniques to both collect and transfer the same embryos in domestic rabbits (Oryctolagus cuniculus), domestic ferrets (Mustela putorius furo) or in any small mammal.

\section{Materials and Methods}

\section{Animals}

Eighteen sexually mature female Dutch belted rabbits, aged 8-14 months and weighing $2.0-2.7 \mathrm{~kg}$, were used for embryo collection and transfer. Eight fertile male Dutch belted rabbits, aged 8-36 months and weighing $2.3-3.0 \mathrm{~kg}$, provided semen for artificial insemination of the embryo donors. The rabbits were raised in our colony and were individually housed under controlled temperature $\left(19-21^{\circ} \mathrm{C}\right)$ and artificial light (12 h light: $12 \mathrm{~h}$ dark) conditions. A diet of pelleted rabbit chow (Prolab High Fiber Rabbit Ration, Agway Inc., Syracuse, NY) and water was provided ad libitum. Animal facilities are approved by the Association for Assessment and Accreditation of Laboratory Animal Care (AAALAC).

Sixty-eight parous female ferrets, aged 8-36 months and weighing $0.6-0.9 \mathrm{~kg}$, were used for embryo collection and transfer. They were surplus animals in a selective breeding programme at Marshall Farms, Inc., North Rose, NY and were culled primarily because of poor mothering ability. All females had conceived at the farm within 2 months before experimental use. At Marshall Farms, the females were kept three to a cage (wire mesh, $30 \mathrm{~cm} \times 60 \mathrm{~cm} \times 60 \mathrm{~cm}$ ) under controlled temperature $\left(20-22^{\circ} \mathrm{C}\right)$ and artificial light $(16 \mathrm{~h}$ light: $8 \mathrm{~h}$ dark) conditions. Marshall Premium Ferret Diet ${ }^{(\oplus)}$ (Bil-Jac Foods, Tulsa, OK) and water were provided ad libitum. Females with vulvar tumescence $>10 \mathrm{~mm}$ in diameter were considered to be in oestrus and were transported to Cornell University, Ithaca, NY and housed under similar conditions for up to $120 \mathrm{~h}$ for embryo collection and up to 3 months for embryo transfer before being killed.

Twelve breeder males, aged 14-24 months and weighing $1.2-1.6 \mathrm{~kg}$, were housed at Cornell individually in cages under the same conditions as the females. All ferrets were fed a diet of Iams Cat Food for Normally Active Cats ${ }^{\circledR}$ (Iams Co., Dayton, $\mathrm{OH}$ ).

\section{Embryo donors and recipients}

Rabbits. Eight embryo donors were superovulated with a combination of follicle stimulating hormone-pituitary (FSHP) and luteinizing hormone ( $\mathrm{LH}$ ), as described by Kennelly and Foote (1965). Coincident with LH administration, embryo donors were artificially inseminated with fresh semen from bucks trained to service an artificial vagina. Semen collected from two males was pooled and examined microscopically to ensure high sperm numbers and $>60 \%$ progressive motility. A $0.1 \mathrm{ml}$ sample of the pooled semen was deposited into the anterior vagina of each doe.

Ten embryo recipient does received an ovulatory i.m. injection of $15 \mu \mathrm{g}$ Gonadorelin diacetate tetrahydrate (Cystorelin ${ }^{*}$, Sanofi Animal Health, Inc., Overland Park, KS) approximately $12 \mathrm{~h}$ after the administration of $\mathrm{LH}$ to the embryo donors. The $12 \mathrm{~h}$ difference in ovulatory injection between embryo donors and recipients was to compensate for the expected delayed development of embryos due to handling in vitro (Maurer et al., 1968).

Ferrets. The 37 females used for embryo collection were each naturally mated with two males following the procedure at Marshall Farms. They were given an ovulatory injection of $100 \mathrm{iu}$ hCG (Chorionic Gonadotropin, Butler Co., Columbus, $\mathrm{OH}$ ) coincident with the first pairing, as described by Mead et al. (1988). Twelve hours after this injection they were paired with a second male for $12 \mathrm{~h}$ to ensure high fertility. Recipient females were given an injection of $100 \mathrm{iu}$ hCG $12-15 \mathrm{~h}$ after the administration of hCG to the embryo donor, irrespective of the time when the embryos were collected from the donor. The $12-15 \mathrm{~h}$ delay from the donors was to compensate for the expected delayed development due to handling of the embryos in vitro.

\section{Preparation of animals for catheterization}

Rabbits and ferrets were anaesthetized with an i.m. injection of $2 \mathrm{ml}$ Xylazine $\mathrm{kg}^{-1}$ (Rompun ${ }^{\circledR}$, Bayer Corp., Shawnee Mission, KS) followed after $5 \mathrm{~min}$ by an i.m. injection of $25 \mathrm{mg}$ Ketamine $\mathrm{HCl} \mathrm{kg}^{-1}$ (Ketaset $^{\left({ }^{(}\right)}$, Fort Dodge Laboratories, Fort Dodge, IA). Catheterization was performed on anaesthetized animals in dorsal recumbency with the caudal third of their body raised $3 \mathrm{~cm}$. The vagina was rinsed with physiological saline containing $5 \%(\mathrm{v} / \mathrm{v})$ antibiotic-antimycotic (Life Technologies Inc., Gibco BRL, Gaithersburg, MD), and a sterile cotton swab was inserted into the vagina to remove any mucus and cellular debris.

\section{Equipment for cervical visualization}

The equipment developed or adapted for catheterizing the rabbit and ferret cervices consisted of an endoscope system 
for visualizing the cervices, a transcervical catheter, and a speculum to house the endoscope and catheter and to provide access to the anterior vagina (Figs 1 and 2). The equipment and catheters were disinfected with $70 \%$ ethanol and rinsed with flushing medium before use on successive animals.

The endoscope system consisted of the following components: a halogen light source (Olympus CLK-3, Olympus America, Inc., Melville, NY); a $2.2 \mathrm{~mm}$ outer diameter, flexible, fibre optic endoscope (Ultrathin Fiberscope $^{\circledast}$, Olympus PF, type 22, Olympus America, Inc., Melville, NY); a black and white video camera (Solid State Camera, Model 4815-5000, Cohu, Inc., San Diego, CA); an adaptor to connect the eyepiece of the fibrescope to the camera (Karl Storz 565CA-243, Karl Storz EndoscopyAmerica, Inc., Culver City, CA); and a black and white television monitor (Audiotronics Model 9VM967, Audiotronics Corp., North Hollywood, CA). Light was transferred through the fibrescope by a fibre bundle providing a source of illumination for the objective lens at the distal end of the fibrescope. The video camera was connected to the eyepiece of the fibrescope via an adaptor, allowing images from the endoscope to be viewed on a television monitor.

\section{Catheterization}

Rabbits. The embryo collection catheter (Fig. 1a) was composed of polyethylene tubing (inner diameter: $1.19 \mathrm{~mm}$ : outer diameter: $1.70 \mathrm{~mm}$; PE-190, Intramedic ${ }^{\circledast}$, Clay Adams, Parsippany, NJ). A $15 \mathrm{~mm}$ long latex sleeve surrounded the distal end of the tubing to serve as a balloon (Fig. 1a). Small diameter polyethylene tubing (inner diameter: $0.28 \mathrm{~mm}$; outer diameter: $0.61 \mathrm{~mm}$; PE-10, Intramedic ${ }^{\circledR}$ ) was inserted under the latex sleeve to serve as an inflation channel, and its proximal end was attached to a $5 \mathrm{ml}$ syringe fitted with a stopcock to prevent backflow of air after balloon inflation. The distal $4 \mathrm{~mm}$ of the collection catheter was inserted and glued into a centre-bored, $4 \mathrm{~mm}$ diameter, clay-polymer bead (Figs 1a and 3) made by the authors. A $0.62 \mathrm{~mm}$ diameter, stainless steel wire (part number T-304V, Small Parts, Inc., Miami Lakes, FL) inserted into the catheter served as a guidewire.

The transfer catheter (Fig. 1b,c) was composed of polyethylene tubing (inner diameter: $0.86 \mathrm{~mm}$; outer diamter: $1.27 \mathrm{~mm}$; PE-90, Intramedic $\left.{ }^{\circledR}\right)$ and had a centrebored, $4 \mathrm{~mm}$ diameter, clay-polymer bead affixed to its distal end. A $0.62 \mathrm{~mm}$ diameter, stainless steel wire served as a guidewire. The transfer catheter was inserted into a $2 \mathrm{~mm}$ diameter stainless steel tube. A $7 \mathrm{~mm}$ outer diameter glass tube with fire-polished ends served as a speculum and was connected to the arm of T- connector, so that a flow of $5 \% \mathrm{CO}_{2}$ in air from a pressurized tank kept the vagina inflated (Fig. 1). The proximal arm of the T-connector was inserted into a vacutainer stopper which served as a cap. A stopper with holes was fitted to permit insertion of the fibrescope and catheter into the speculum.

Because the rabbit has a duplex uterus consisting of two separate uteri, each with its own cervix, each rabbit had to be catheterized twice to collect embryos and twice to transfer (a)
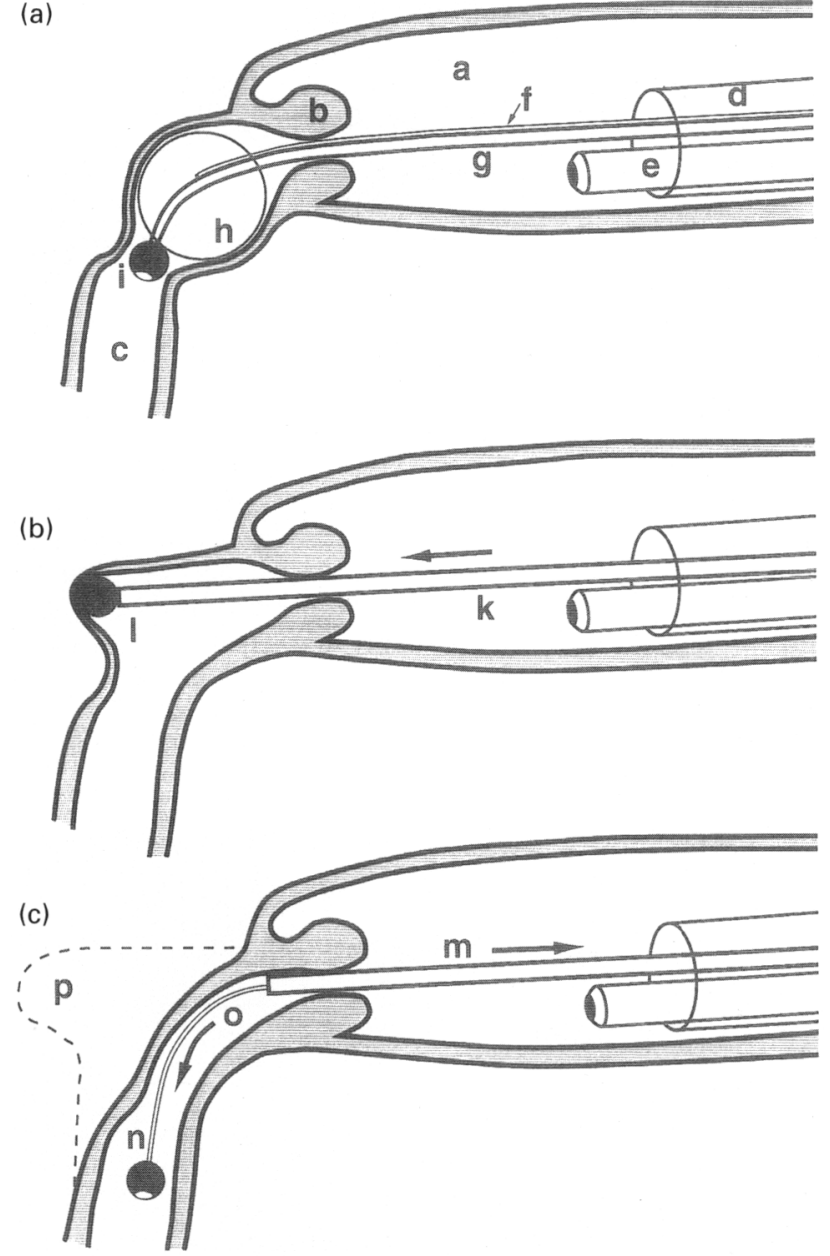

Fig 1. (a) Visualization of the rabbit cervix and insertion of the embryo collection catheter into the uterus. a, Anterior vagina inflated with $5 \% \mathrm{CO}_{2}$ in air; b, cervix; c, lumen of uterus; $d$, speculum; e, fibre-optic endoscope; $f$, balloon inflation tubing; $g$, flush-collection tubing; $h$, inflated balloon; $i$, clay polymer bead. The external surface of the speculum was lubricated with sterile Surgilube ${ }^{\circledast}$ (E. Fougera and Co., Melville, NY), and the speculum was gently inserted into the vagina and worked forward through the pelvic arch until it reached the cervix. The endoscope permitted visualization of the anterior vagina and cervices on a television monitor. (b) The initial insertion of the embryo transfer catheter into the uterus. The embryo transfer catheter was inserted into a stainless-steel tube (k) so that only the clay polymer bead (l) on its distal end was evident. The tube provided the necessary rigidity for the catheter bead to traverse the cervix and distend the uterine wall. (c) Positioning the embryo transfer catheter. The stainless steel tubing was withdrawn (m) while the transfer catheter (n) was simultaneously pushed forward (o), resulting in placement of the transfer catheter bead well beyond the internal cervix. The distended uterine wall ( $p$ ) assumes its original shape with the withdrawal of the stainless steel tubing.

embryos. The procedures for cervical catheterization are illustrated (Fig. 1). Both cervices and uteri were catheterized. A stainless steel guidewire was inserted into the collection catheter to increase its rigidity while allowing it to remain flexible. Under visual guidance, the catheter was oriented so that the bead was apposed to the external cervical os. Gentle 


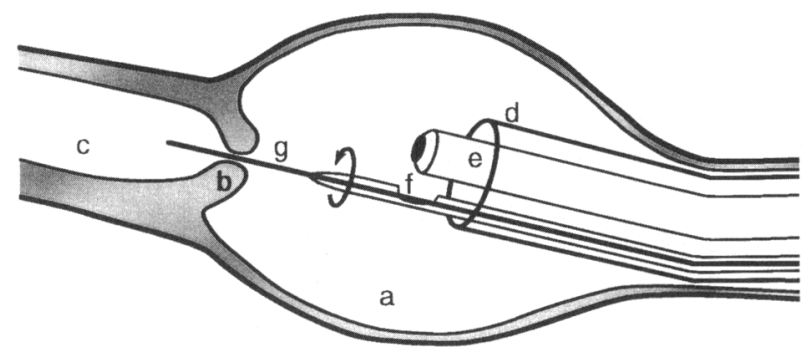

Fig. 2. Visualization of the ferret cervix and insertion of the embryo collection-transfer catheter. a, anterior vagina inflated with $5 \% \mathrm{CO}_{2}$ in air; $b$, cervix; $c$, lumen of uterine body; $d$, speculum $(5.0 \mathrm{~mm}$ outer diameter); e, fibre-optic endoscope; $\mathrm{f}$, catheter $(1.27 \mathrm{~mm}$ outer diameter) with portal for passage of embryos; $g$, catheter guidewire $(0.37 \mathrm{~mm})$. The external surface of the speculum was lubricated with sterile Surgilube ${ }^{(E)}$ (E. Fougera and Co., Melville, NY), and the speculum was gently inserted into the vagina and worked forward through the pelvic arch until it reached the cervix. The endoscope permitted visualization of the anterior vagina and cervix on a television monitor.

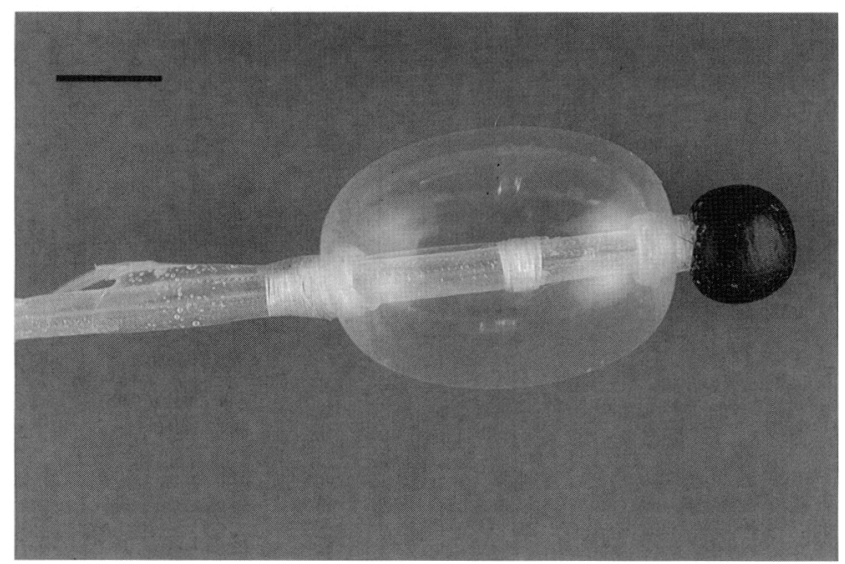

Fig. 3. Close-up of the distal end of the embryo collection catheter with inflated balloon. Scale bar represents $5 \mathrm{~mm}$.

forward pressure of the catheter resulted in the external cervix enveloping the bead, and continued forward pressure, while withdrawing the guidewire, introduced the bead and catheter into the uterus. The bead was used to facilitate movement of the catheter into and through the cervix and, because the uterus turns sharply immediately beyond the cervix, to avoid perforating the uterine wall. The catheter was marked with a black ring $1 \mathrm{~cm}$ posterior to the balloon; when the catheter was moved into the cervix far enough to obscure the ring, the balloon was inflated (Fig. 1a) to provide a seal and prevent loss of flushing medium. The endoscope and speculum were then withdrawn.

The embryo transfer catheter was sheathed in a stainless steel tube to facilitate cervical passage and catheter placement. The tube served the same function as a guidewire but provided greater rigidity. When the bead was pushed against the external cervical os, the bead and tubing traversed the cervix, and continued forward pressure distended the uterine wall and pushed the reproductive tract anteriorly (Fig. 1b).
The tubing was slowly withdrawn from the cervix, while the catheter was simultaneously advanced (Fig. 1c), which permitted placement of the embryos anterior to the cervix.

Ferrets. The catheter was composed of polyethelene tubing (inner diameter: $0.86 \mathrm{~mm}$; outer diameter: $1.27 \mathrm{~mm}$ ) (PE-90, Intramedic ${ }^{\sqrt{ }}$ ). A $0.37 \mathrm{~mm}$ diameter, stainless steel, wire (part number T-304V, Small Parts, Inc.) inserted into the $30 \mathrm{~cm}$ catheter served as a guidewire. A tapered catheter tip was formed at one end of the tubing by heating the tubing at the end and gently pulling it. An oval hole approximately $2 \mathrm{~mm} \times 1 \mathrm{~mm}$ was cut $8 \mathrm{~mm}$ from the tip of the tapered end of the catheter to permit embryo collection and transfer (Kidder, 1998) for a photograph of the catheter.

The speculum (Fig. 2) was made from a modified $25 \mathrm{~mm} \times$ $5 \mathrm{~mm}$ outer diameter, plastic, French straw sheath (Model ZL 302, Instruments de Medecine Veterinaire Corp., L'Aigle). The sheath was cut to $10.5 \mathrm{~cm}$ in length, and the distal $2 \mathrm{~cm}$ was bent at an angle of approximately $50^{\circ}$. The distal $2 \mathrm{~mm}$ of the sheath was manufactured with a slight taper, which facilitated its passage through the vagina with little abrasion or snagging. The speculum was connected to the arm of a T-connector and assembled as described for the rabbit.

The speculum and fibrescope were gently manipulated until a rectilinear view of the cervix could be obtained. The guidewire was used to locate the cervical os, and it was gently pushed through the cervix. Care was taken to ensure that the guidewire was not extended far enough out of the catheter to perforate the uterine wall. The catheter was gently twisted forward into the uterus (Fig. 2). The catheter was marked with a black ring $1 \mathrm{~cm}$ from its tip; when the catheter was moved into the cervix far enough to obscure the ring, the hole in the catheter tip was in the lumen of the uterine body. The guidewire, endoscope and speculum were then withdrawn, and flushing medium was introduced into, and retrieved from, the uterus through the catheter.

\section{Embryo collection and transfer}

Rabbits. After catheterization, each uterus of the eight embryo donors was flushed five times (Fig. 1a) with 1-4 ml RD medium (Carney and Foote, 1990) 78-89 h after an ovulatory injection of $\mathrm{LH}$. The RD medium contained $25 \mathrm{mmol}$ Hepes buffer $\mathrm{l}^{-1}, 1.0 \%(\mathrm{w} / \mathrm{v})$ polyvinyl alcohol, and $0.1 \%(\mathrm{v} / \mathrm{v})$ antibiotic-antimycotic (Life Technologies Inc.). The donor was angled upwards approximately $25^{\circ}$ and flushing medium was introduced to carefully inflate each uterus until it was turgid by a syringe connected to a Tomcat $^{\text {cather }}$ catheter (Sherwood Medical Co., St Louis, MO) attached to the end of the cervical collection catheter. The uterus was gently straightened by palpation through the abdominal wall, and the catheter balloon was held and manipulated to facilitate collection of the flushing medium. All flushes were examined microscopically, the embryos were pooled, and they were washed three times with $R D$ medium. The embryos were held in vitro in covered dishes of $\mathrm{RD}$ medium at ambient temperature for up to $2 \mathrm{~h}$ before transfer, while all flushes were completed. Embryo donors were killed by an i.p. injection of $100 \mathrm{mg}$ pentobarbital 
sodium $\mathrm{kg}^{-1}$ body weight (Beuthanasia-D ${ }^{\sqrt{3}}$, Schering-Plough Corp., Madison, NJ), and their ovaries were examined for ovulatory response.

The hindquarters of recipients were raised $3 \mathrm{~cm}$ during the transfer procedure to facilitate transfer of embryos. The catheter was manipulated forward in the uterus so that embryos were deposited beyond the cervix (Fig. 1b,c). Ten to twelve embryos were aspirated into a $25 \mu l$ microcapillary tube so that they were in a $5-10 \mu \mathrm{l}$ drop situated between two air bubbles and $3 \mu$ of medium was added at the tip of the tube. Up to $20 \mu \mathrm{l}$ of medium, together with the embryos, was expelled from the catheter and into the uterus. Embryos from eight donors were transferred to ten recipients.

Embryo recipients were maintained in cages and provided with a nest box and straw 2 days before their date of expected parturition. Females were checked frequently on their date of expected parturition. When young were found, their number and condition were recorded. Mothers and their offspring remained in the colony.

Ferrets. Uteri of each of the 37 embryo donors were flushed ten times with 1-3 $\mathrm{ml}$ RD medium $145-178 \mathrm{~h}$ after an ovulatory injection of hCG. The donor was held with its body angled upwards approximately $25^{\circ}$. Flushing medium was carefully introduced to inflate the uterus by a syringe connected to a Tomcat ${ }^{\sqrt[B]{B}}$ catheter attached to the end of the cervical catheter.

The uterine horns were compressed by pressure on the abdominal wall, and the catheter was gently manipulated to facilitate collection of the flushing medium into a $60 \mathrm{~mm} \times 15 \mathrm{~mm}$ dish (Falcon ${ }^{\star}$, Becton Dickinson Co., Franklin Lakes, NJ). Embryos in the ten flushes were examined, pooled and washed three times with RD medium.

Embryo recipients were catheterized in the same manner as the embryo donor but with their hindquarters raised. Five to fourteen embryos were aspirated into a $25 \mu \mathrm{l}$ microcapillary tube as described for the rabbit. Embryos were deposited with the catheter only in the uterine body or just anterior to the uterine body to avoid possible irritation of the uterus.

Embryos from 27 donors were transferred to 31 recipients. Fourteen sets of embryos for transfer were flushed and held in RD medium containing $2.5 \mathrm{mmol}$ Hepes buffer $\mathrm{l}^{-1}$ (Sigma Chemical Co., St Louis, MO), and 13 sets were flushed and held in RD medium containing 25 mmol Hepes buffer $\mathrm{l}^{-1}$. The embryos flushed with the medium containing $2.5 \mathrm{mmol}$
Hepes buffer $\mathrm{l}^{-1}$ were held in an incubator containing $5 \% \mathrm{CO}_{2}$ in air, while those flushed with medium containing $25 \mathrm{mmol}$ Hepes buffer $\mathbf{l}^{-1}$ were exposed to the air. Embryos were held for $0.75-2.50 \mathrm{~h}$ before being transferred.

Embryo recipients were maintained individually in cages provided with a dark nest box and blanket. Females were checked frequently on their date of expected parturition. When kits were found, their number, weight and condition were recorded. Females that failed to conceive were killed by an i.p. injection of $100 \mathrm{mg}$ pentobarbital sodium $\mathrm{kg}^{-1}$ body weight (Beuthanasia- $D^{*}$ ) on day 43 of expected pregnancy, and their reproductive tracts were excised and examined for evidence of pregnancy. Mothers and kits either were killed shortly after parturition, or remained in the colony until the kits were weaned.

\section{Statistical analysis}

In rabbits, eight and ten replications of embryo collection and embryo transfer, respectively, were used to calculate means \pm SEM. In ferrets, 31 replications of embryo collection and embryo transfer were used to calculate means \pm SEM.

\section{Results}

\section{Rabbits}

A total of 187 embryos (morulae to expanding blastocysts) were collected from five transcervical flushes of each uterine horn of eight rabbits (Table 1). The average number of embryos collected per rabbit was 23 (range 13-30), and the range in total number of embryos collected in any single flush from the eight donors was 23-69 (Table 1).

Embryos from the eight donors were transferred to the uteri of ten recipients (Table 2). A total of 116 embryos transferred resulted in eight recipients delivering 23 young. The average litter size was 2.88 (range 1-7).

\section{Ferrets}

A total of 324 embryos (morulae to expanding blastocysts) were collected from ten transcervical uterine flushes of 37

Table 1. The total and mean number of embryos collected from each of ten nonsurgical, uterine flushes (five per uterine horn) in eight domestic rabbits

\begin{tabular}{lccccc}
\hline & \multicolumn{5}{c}{ Flush number } \\
\cline { 2 - 6 } Embryos & 1 & 2 & 3 & 4 & 5 \\
\hline Total number & 27 & 23 & 41 & 27 & 69 \\
Mean number \pm SEM & $3.37 \pm 1.6$ & $2.88 \pm 1.2$ & $5.12 \pm 1.6$ & $3.37 \pm 1.1$ & $8.62 \pm 1.7$ \\
Percentage of total & 14 & 12 & 22 & 14 & 37 \\
Maximum number & 11 & 9 & 16 & 9 & 14 \\
\hline
\end{tabular}

The total number of embryos collected from all flushes in all rabbits was 187. 
Table 2. Summary of nonsurgical, uterine embryo collection and transfer in domestic rabbits and domestic ferrets

\begin{tabular}{|c|c|c|}
\hline Variable & Rabbit & Ferret \\
\hline Number of embryo donors & 8 & 27 \\
\hline Number of embryo recipients & 10 & 31 \\
\hline Number $(\%)$ initially pregnant ${ }^{a}$ & $8(80)$ & $28(90)$ \\
\hline Number $(\%)$ that produced live young & $8(80)$ & $22(71)$ \\
\hline Number of corpora lutea $^{b}$ & 265 & 389 \\
\hline Number $(\%)$ of embryos obtained ${ }^{c}$ & $187(71)$ & $278(71)$ \\
\hline Number of embryos transferred & 116 & 251 \\
\hline Number $(\%)$ of young ${ }^{d}$ & $23(20)$ & $65(26)$ \\
\hline Number of young per litter & 2.88 & 2.95 \\
\hline
\end{tabular}

Includes ferrets that did not produce live young but had evidence of resorption.

'Rabbits were superovulated.

'Includes unfertilized ova and degenerate embryos.

${ }^{\mathrm{d}}$ Four ferret kits were found dead; they were full-term and exhibited normal development.

female ferrets (Table 3). The largest number of embryos collected in any flush was a total of 63 in the first flush from 37 ferrets, with only 12 in the ninth flush. The largest number of embryos collected from a single ferret was 17 .

Embryos ranging from morulae to expanding blastocysts from 27 donors were transferred to the uteri of 31 recipients (Table 2). A total of 251 embryos transferred resulted in 28 ferrets initially pregnant and 22 ferrets delivering 65 young. The average litter size was 2.95 (range 1-7).

Embryos pooled from ten transcervical uterine flushes from the uterus of a single female $148 \mathrm{~h}$ after an ovulatory injection of hCG are shown (Fig. 4). The variation in size of embryos shown was typical for most animals.

\section{Discussion}

Catheterization of the two cervices in rabbits is difficult unless a system is devised to visualize them. The only report of transcervical catheterization in the rabbit has been provided by Testart (1969). Details of Testart's procedure were not provided, but it is likely that the method involved laparotomy, as reported by Dauzier (1962). Testart (1969) transferred day 4 blastocysts to 12 animals. Only eight had implantations on day 11 after transfer, and five of the eight recipients with implantations had uterine infections.
Rabbit cervices are large and their external ora project into the vaginal lumen, making them easy to visualize and differentiate with the endoscope. The external os has a rosette-like appearance resulting from the longitudinal folds of the cervical mucous membrane (Suzuki et al., 1978). When the bead on the end of the transcervical catheter was oriented so that it was apposed to the external os, gentle forward pressure of the catheter introduced the bead and catheter into the uterus in all rabbits studied.

Morulae were collected from $78-82 \mathrm{~h}$, blastocysts from $78-87 \mathrm{~h}$, and expanding blastocysts from $86-89 \mathrm{~h}$ after $\mathrm{LH}$ in rabbits. The efficiency of embryo collection, expressed as the percentage of corpora lutea represented by embryos (or unfertilized ova), ranged from 54 to $81 \%$. Surgical recovery of blastocysts from the rabbit uterus averaged $48 \%$ (C. J. Schacht and R. H. Foote, unpublished).

Several factors may explain the large increase in the number of embryos collected in the fifth flush. At 78-89 h after $\mathrm{LH}$, many embryos are likely to be in the upper part of the oviduct (Boving, 1956; Tsutsumi and Hafez, 1974). In the present study, the right uterus of one rabbit was flushed at $72 \mathrm{~h}$ and yielded no embryos, but when flushed again at $85 \mathrm{~h}$, 19 embryos were recovered. It is likely that many of the embryos collected in the present study were in the anterior half of the uterus at the time of their collection. Successive flushes may have moved the embryos toward the cervix and collection. In addition, a greater effort in palpating and compressing the uterus on the last flush probably contributed to the increase in embryos recovered.

The number of flushes was limited to five in each uterus (ten per donor) to minimize the amount of time rabbit embryos were held in vitro before transfer. Because of the time required for catheterizing and flushing each uterus, and for examining and pooling recovered embryos, they were held for up to $2 \mathrm{~h}$ before being transferred. Eight out of ten recipients became pregnant (Table 2 ), but only $20 \%$ of the embryos transferred resulted in the birth of young. The average litter size of 2.88 was small relative to the average litter size from natural mating. In comparison, surgical transfer of blastocysts to the uteri of recipients, with a similar holding time for manipulation, resulted in $24-44 \%$ births, with average litter sizes of 2.9 (Yang and Foote, 1987).

Further research is necessary to maximize the efficiency of the transcervical transfer technique. Deposition of the $78-89 \mathrm{~h}$ rabbit embryos into the anterior end of the uterus might have improved results. Adams (1982) observed that when large blastocysts are transferred shortly before

Table 3. The total and mean number of embryos collected from each of ten nonsurgical, uterine flushes in 37 domestic ferrets

Flush number

\begin{tabular}{lcccccccccc}
\cline { 2 - 7 } Embryos & 1 & 2 & 3 & 4 & 5 & 6 & 7 & 8 & 9 \\
\hline Total number & 63 & 45 & 49 & 31 & 32 & 26 & 25 & 17 & 12 \\
Mean number \pm SEM & $1.7 \pm 0.4$ & $1.22 \pm 0.2$ & $1.32 \pm 0.3$ & $0.84 \pm 0.2$ & $0.87 \pm 0.2$ & $0.70 \pm 0.2$ & $0.68 \pm 0.2$ & $0.46 \pm 0.1$ & $0.32 \pm 0.1$ & $0.65 \pm 0.2$ \\
Percentage of total & 19 & 14 & 15 & 10 & 10 & 8 & 8 & 5 & 4 & 7 \\
Maximum number & 7 & 5 & 9 & 5 & 7 & 6 & 7 & 4 & 3 \\
\hline
\end{tabular}

The total number of embryos collected from all flushes in all ferrets was 324 . 


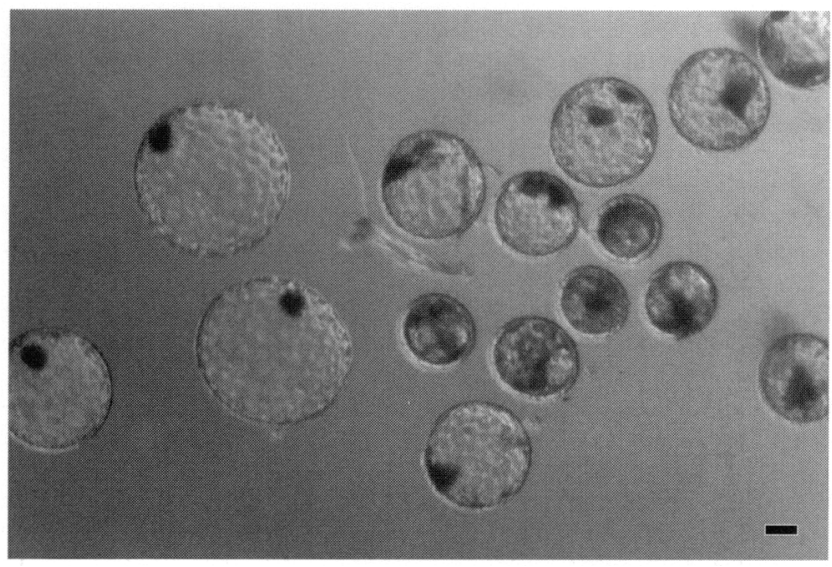

Fig. 4. Fifteen domestic ferret blastocysts collected from the uterus of a single female through transcervical uterine flush. The embryos were photographed immediately after collection, approximately $148 \mathrm{~h}$ after an ovulatory injection of hCG. Note the substantial variation in size and development typical of ferret embryos collected at a standard interval after hCG. Scale bar represents $100 \mu \mathrm{m}$.

implantation, problems of spacing resulted in increased mortality. It is possible that spacing was similarly retarded when younger embryos were deposited into the caudal portion of the uterus. The use of a modified balloon catheter, which could be held through the abdominal wall and manipulated forward in the uterus, might result in more anterior deposition of embryos.

The difficulty in transversing the cervix has essentially prevented nonsurgical embryo collection and transfer in small mammals. In the one previous report of nonsurgical embryo collection in a carnivore (Hurlbut et al., 1988), 12 successful transcervical catheterizations in 17 attempts were made and three blastocysts were obtained on one occasion in domestic cats. In addition, there is one report of transcervical embryo transfer in domestic cats (Swanson and Godke, 1994) in which embryo transfer tubing was inserted through a transcervical catheter into the uterus in seven of eight cats. Four to nine morulae produced in vitro were transferred to each of seven recipients, and one recipient gave birth to three full-term kittens 61 days after embryo transfer.

The methods reported in the present study facilitated transcervical catheterization in ferrets in $85 \%$ of attempts. The average time to catheterize a ferret cervix was $7 \mathrm{~min}$ (range 2-20 min). Because the ferret cervix appears slightly depressed relative to the plane of the speculum through the pelvis, a slight bend was made in the distal end of the speculum. Manipulation of the speculum usually provided a rectilinear view of the cervix, allowing catheterization. Unsuccessful catheterization was attributed to tissue folds obscuring the cervical os and, most often, failure to align the stylette with the cervical canal. The catheterization methods reported in this paper have also enabled successful transcervical artificial insemination in domestic ferrets (Kidder et al., 1998).

Only two of the 37 ferrets flushed in the present study failed to yield embryos, and these animals had infantile reproductive organs. The greatest number of embryos collected from an individual was 17 . Forty-eight per cent of the embryos were collected in the first three flushes and $17 \%$ were collected in the last three flushes. The increase in the number of embryos collected in flush ten is likely due to a greater effort made in palpating and compressing the uterus on this final flush. This finding indicates that when initial flushes are marginally successful, additional flushes are warranted.

Seventy-one per cent of ferret corpora lutea were represented by embryos (or unfertilized ova) collected through transcervical flushes. Some ova may not have been retrieved because unfertilized ova are transported more slowly through the oviducts than are embryos (Mead et al., 1988).

The rate of ferret embryo development varied. Expanding blastocysts were collected as early as $149 \mathrm{~h}$ and morulae as late as $157 \mathrm{~h}$ after hCG injection. Hamilton (1934) found incipient blastocysts in the uterus on day 6 after mating, and Marston and Kelly (1969) reported both morulae and blastocysts at 7 days after mating. Chang (1968) recovered mainly tubal morulae on day 6 after hCG injection and mainly blastocysts in the uterus on day 7. Blastocysts expand rapidly in ferrets (McRae, 1992; Kidder, 1998), and catheter size was limited to accommodate blastocysts 7 days after mating.

The variability in ferret embryo development may have been due to time of fertilization, but attempts were made to control ovulation time with an injection of hCG at the time of the first mating. Females were left with the males for $12 \mathrm{~h}$ and then paired with a second male for $12 \mathrm{~h}$ to ensure high fertility, a procedure similar to the two-male mating system used commercially. In most cases, copulation was observed within 30 min of pairing

Twenty-six per cent of ferret embryos transferred resulted in the birth of kits. Ninety per cent (28 of 31) of recipients were initially pregnant. While only $71 \%$ (22 of 31 ) of recipients produced young, necropsy revealed that 19\% (6 of 31 ) that were initially pregnant, but did not give birth, had evidence of fetal resorption. Many of the recipients that gave birth also showed signs of fetal resorption. Evidence of resorption included implantation sites, placental discs, necrotic debris, and degenerating fetuses. There was no indication of uterine infection, nor any sign of trauma to the cervix or uterus associated with catheterization.

The average litter size of 2.95 kits was small relative to the average litter size from natural mating of ferrets. However, the ferrets used in this study were culls, and they produced an average of only $6.5 \mathrm{kits}$ in their preceding litter. These results represent embryos that had been held in the $R D$ flushing medium for up to $2.5 \mathrm{~h}$, as the ten embryo flushes of the 27 donors used for embryo transfer required $0.75-2.50 \mathrm{~h}$ to complete. While the embryos were not examined in detail, there did not appear to be any changes in the embryos while in the culture medium. In a separate study, ferret embryos held overnight in RD medium appeared to be normal (J. D. Kidder and R. H. Foote, unpublished).

The initial 14 sets of transferred ferret embryos were flushed with RD medium containing 2.5 mmol Hepes $\mathrm{l}^{-1}$, and the embryos were held in a $\mathrm{CO}_{2}$ incubator to maintain the $\mathrm{pH}$. An additional 13 sets of transferred embryos were

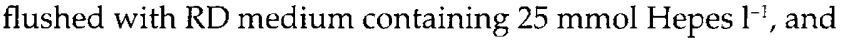
no $\mathrm{CO}_{2}$ was required to maintain the $\mathrm{pH}$. When only the embryos in the $25 \mathrm{mmol}$ Hepes $\mathrm{l}^{-1}$ buffer treatment were 
considered, the average litter size was $3.36 \mathrm{kits}$, indicating that the RD medium was compatible with embryo survival for at least several hours in a medium without $\mathrm{CO}_{2}$.

The birth weights of the ferret kits produced were consistent with kits born at Marshall Farms, averaging $10 \mathrm{~g}$ (range 8-13 g), and exhibited normal growth and development (Kidder, 1998).

In conclusion, the results of this study are encouraging and have demonstrated the feasibility of transcervical catheterization and concomitant nonsurgical embryo collection and transfer in domestic rabbits and domestic ferrets. The procedures described should be applicable to interspecific embryo transfer between black-footed ferret (Mustela nigripes) donors and domestic ferret recipients. The two nonsurgical embryo collection and transfer systems described, with modifications to accommodate species differences, have application to a wide range of mammals, particularly endangered species. This is the first report of successful nonsurgical, intrauterine collection of embryos and transfer of those same embryos in a small mammal.

The authors thank A. Fleischaker and the Olympus Corporation for their generous loan of the fibrescope and light source; G. Marshall and the staff of Marshall Farms for supplying the ferrets used in this study, particularly M. Salerno and J. Bell for their cordial assistance and advice on ferret husbandry; $\mathrm{L}$. Donaldson for the $\mathrm{LH}$; $\mathrm{X}$. Yang and J-C. Ju for their technical assistance; P. Reynolds, A. Wenski-Roberts, and B. Tefft for graphic contributions; J. Wu for her help with maintenance of the ferret colony; and R. Mead for helpful comments on the manuscript. This research was supported by the New York Cooperative Fish and Wildlife Research Unit and the Department of Animal Science at Cornell University.

\section{References}

Adams CE (1956) A study of fertilization in the rabbit: the effect of post-coital ligation of the Fallopian tube or uterine horn Journal of Endocrinology 13 296-308

Adams CE (1962) Studies on prenatal mortality in the rabbit, Oryctolagus cuniculus, the effect of transferring varying numbers of eggs journal of Endocrinology 24 471-490

Adams CE (1982) Egg transfer in the rabbit. In Mammalian Egg Transfer pp 29-48 Ed. CE Adams. CRC Press, Boca Raton

Anderson GB (1983) Embryo transfer in domestic animals Advances in Veterinary Science and Comparative Medicine 27 129-162

Boving BG (1956) Rabbit blastocyst distribution American Journal of Anatomy $98403-434$

Carney EW and Foote RH (1990) Effects of superovulation embryo recovery culture system and embryo transfer on development of rabbit embryos in vivo and in vitro. Joumal of Reproduction and Fertility 89 543-552

Chang MC (1950) Development and fate of transferred rabbit ova or blastocysts in relation to the ovulation time of the recipients Journal of Experimental Zoology 114 197-226

Chang MC (1968) Reciprocal insemination and egg transfer between ferrets and mink Journal of Experimental Zoology $16849-60$

Dauzier L (1962) Nouvelles données sur la transplantation des œufs, chez la lapine, par voie vaginale ou intrapéritonéale Annales de Biologie Anintale, Biochimie, et Biophysique 2 17-23

Dukelow WR (1971) Laparoscopic research techniques in mammalian embryology. In Methods in Mammalian Embryology pp 442-460 Ed. JC Daniel. WH Freeman, San Francisco, CA

Foote RH (1987) In vitro fertilization and embryo transfer in domestic animals: applications in animals and implications for humans Journal of In Vitro Fertilization and Embryo Transfer 473-88

Gajda B, Jura J and Smorag Z (1988) Nonsurgical embryo collection in rabbits Zuchthygiene (Berlin) 23 149-153
Hafez ESE (1962) Effect of progestational stage of the endometrium on implantation, fetal survival and fetal size in the rabbit, Oryctolagus cuniculus. Journal of Experimental Zoology 151 217-226

Hamilton WJ (1934) The early stages in the development of the ferret. Fertilization to the formation of the pro-chordal plate Transactions of the Royal Society of Edinburgh 58 251-278

Heape W (1890) Preliminary note on the transplantation and growth of mammalian ova within a uterine foster mother Proceedings of the Royal Society of London $48457-458$

Hurlbut SL, Bowen MJ and Kraemer DC (1988) The feasibility of transcervical catheterization and nonsurgical embryo collection in the domestic cat Theriogenology 29264

Kennelly JJ and Foote RH (1965) Superovulatory response of pre- and postpubertal rabbits to commercially available gonadotropins Journal of Reproduction and Fertility 9 177-188

Kidder JD (1998) Development of Nonsurgical Reproductive Biotechnologies in Domestic Ferret and Rabbit Models and Characterization of Cell Allocation to the Preimplantation Blastocyst of the Domestic Ferret PhD Thesis, Cornell University

Kidder JD, Foote RH and Richmond ME (1998) Transcervical artificial insemination in the domestic ferret (Mustela putorius furo) Zoo Biology 17 393-404

McRae A (1992) Effect of ovariectomy on blastocyst expansion and survival in ferrets (Mustela putorius furo) Reproduction Fertility and Development 4 239-247

Marston JH and Kelly WA (1969) Contraceptive action of intrauterine devices in the ferret Journal of Reproduction and Fertility 18 419-429

Maurer RR, Hunt WL, Van Vleck LD and Foote RH (1968) Developmental potential of superovulated rabbit ova Journal of Reproduction and Fertility 15 171-175

Mead RA, Joseph MM and Neirinckx S (1988) Optimal dose of human chorionic gonadotropin for inducing ovulation in the ferret Zoo Biology 7 263-268

Pincus G and Enzmann EV (1932) Can mammalian eggs undergo normal development in vitro? Proceedings National Acadamy of Sciences USA 20 121-122

Seidel GE, Jr (1981) Superovulation and embryo transfer in cattle Science 211 351-358

Suzuki H, Takeda T and Tsutsumi Y (1978) Gross and microscopic features of the cervix in the non-pregnant rabbit Japanese Journal of Zootechnical Science $49614-624$

Swanson WF and Godke RA (1994) Transcervical embryo transfer in the domestic cat Laboratory Animal Science 44 288-291

Takeda T, Tsutsumi Y, Tanabe $Y$ and Yamamoto K (1977) Administration of prostaglandin $F_{2 u}$ for the recovery of fertilized eggs from the vaginas of rabbits Fertility and Sterility 28 759-761

Takeda T, Suzuki H, Terami $Y$ and Tsutsumi Y (1979) Egg recovery from the vagina of the rabbit treated with prostaglandin $\mathrm{F}_{2 \alpha}$ Japanese Journal of Animal Reproduction 25 23-30

Testart J (1969) Comparision de différentes techniques de transplantation des blastocystes chez la lapine Annales de Biologie Animale, Biochimie, et Biophysique $9351-360$

Torres $\mathbf{S}$ and Sevellec $\mathbf{C}$ (1987) Repeated superovulation and surgical recovery of embryos in the ewe Reproduction Nutrition Developpement $27859-863$

Tsutsumi Y and Hafez ESE (1974) Distribution patterns of rabbit embryos during preimplantation stage Journal of Morphology 144 323-336

Tsutsumi Y, Takeda T, Yamamoto K and Tanabe $Y$ (1976) Nonsurgical recovery of fertilized eggs from the vagina of oestrogen-treated rabbits Jounal of Reproduction and Fertility 48 393-395

Tsutsumi Y, Terami Y, Suzuki $H$ and Saito S (1979) Effects of prostaglandin $\mathrm{F}_{20 \mathrm{x}}$ on egg recovery from the vagina and egg transport in superovulated rabbits fournal of the Faculty of Agriculture Hokkaido University 59 312-321

Wildt DE (1980) Laparoscopy in the dog and cat. In Animal Laparoscopy pp 31-72 Eds RM Harrison and DE Wildt. Williams and Wilkins, Baltimore

Wildt DE and Goodrowe KL (1989) The potential for embryo technology in the black-footed ferret. In Conservation Biology and the Black-Footed Ferret pp 160-176 Ed. US Seal. Yale University Press, New Haven

Wildt DE, Schiewe MC, Schmidt PM, Goodrowe KL, Howard JG, Phillips LG, O'Brien SJ and Bush M (1986) Developing animal model systems for embryo technologies in rare and endangered wildlife Theriogenology 25 $33-52$

Yang $X$ and Foote RH (1987) Production of identical twin rabbits by micromanipulation of embryos Biology of Reproduction 37 1007-1014 